\title{
Determinants of Preclinical Atherosclerosis Are Different in Type 1 and Type 2 Diabetic Women
}

\author{
P. PIŤHOVÁ ${ }^{1}$, K. ŠTECHOVÁ ${ }^{1}$, J. PIŤHA ${ }^{2}$, V. LÁNSKÁ ${ }^{3}$, M. KVAPIL $^{1}$
}

${ }^{1}$ Clinic of Internal Medicine, Second Medical Faculty and Teaching Hospital Motol, Charles University, Prague, Czech Republic, ${ }^{2}$ Laboratory for Atherosclerosis Research, Institute for Clinical and Experimental Medicine, Prague, Czech Republic, ${ }^{3}$ Statistical Department, Institute for Clinical and Experimental Medicine, Prague, Czech Republic

Received February 22, 2015

Accepted May 28, 2015

On-line October 8, 2015

\section{Summary}

Diabetes mellitus type 2 ranks among the strongest predictors of cardiovascular diseases (CVD) while the association of type 1 diabetes with CVD is more complex. We studied differences between type 1 and 2 diabetic women regarding association of cardiovascular risk factors with preclinical atherosclerosis expressed as intima-media thickness of common carotid (IMT CCA) and femoral arteries (IMT CFA) measured by high resolution ultrasound. Women with type $1(n=203)$ and type 2 diabetes $(n=123)$ were examined with regard to the presence of cardiovascular risk factors. In type 1 diabetic women strong association between IMT CCA and body mass index, waist circumference, and total body fat was found in contrast to type 2 diabetic women. In type 2 diabetic women strong association between IMT CCA and fasting glucose, glycated hemoglobin, and atherogenic index of plasma (log TG/HDL cholesterol) was observed in contrast to type 1 diabetic women. In type 1 diabetic women, IMT CFA was associated with body fat in contrast to type 2 diabetic women. Preclinical atherosclerosis in type 1 diabetic women was strongly associated with factors reflecting body fat and its distribution, while in type 2 diabetic women preclinical atherosclerosis was associated with markers reflecting glucose and lipid metabolic disorders.

\section{Key words}

Type 1 diabetes mellitus - Type 2 diabetes mellitus • Carotid intima-media thickness • Risk factors • Subclinical atherosclerosis

\section{Corresponding author}

P. Pit’hová, Interní klinika 2. LF UK a FN v Motole, V Úvalu 84, 15006 Praha 5, Czech Republic.

E-mail: pavlina.pithova@fnmotol.cz

\section{Introduction}

Atherosclerosis and its main consequence cardiovascular disease (CVD) - is the leading cause of mortality in European countries. The high incidence and prevalence of cardiovascular disease is in general population associated with several main risk factors like age, male sex, genetic factors, smoking, dyslipidemia, hypertension and diabetes mellitus (Munger and Hawkins 2004). Diabetes mellitus ranks among the strongest predictors of cardiovascular diseases (Diabetes Drafting Group 1998). In diabetic patients, smaller vessels are involved more extensively than in non-diabetic populations and atherosclerosis seems to be more aggressive than in non-diabetic population (Haffner et al. 1998).

Beside the severe microvascular complications, patients with type 2 diabetes mellitus (T2DM) are at increased risk of macrovascular complications (Berenson et al. 1998, Booth et al. 2006, Dailey and Wang 2014).

Hyperglycemia has atherogenic effects that lead to the development of atherosclerosis in subjects with T2DM, based on cross-sectional and longitudinal analyses. In those studies, the serum glycated albumin level and the ratio of glycated albumin to glycated hemoglobin (HbAlc) were identified as potential surrogate parameters that are associated with or predict the progression of atherosclerosis in T2DM subjects (Kim et al. 2012, Moon et al. 2012, Song et al. 2012).

While in diabetes mellitus type 2 the mechanisms of atherosclerosis and CVD are rather well described, the association of type 1 diabetes mellitus (T1DM) with CVD 
is more complex and the most important risk factor seems to be insulin resistance. Patients suffering from T1DM could demonstrate the presence of insulin resistance as well. There exists a term of "double diabetes" in literature. Therefore, several factors could underlie the phenotype of double diabetes. The genetic and lifestyle factors that lead to T2DM may exist at similar frequency in those with T1DM. The weight gain and exogenous insulin therapy might induce insulin resistance in patients with T1DM (Cleland et al. 2013). Insulin resistance seems to predict the premature manifestation of cardiovascular disease rather than glucose control parameters in T1DM patients (Schauer et al. 2011).

Although atherosclerosis manifests clinically in middle and late adulthood, it is now accepted that the disorder has a prolonged insidious course, and has its onset early in life. Identification of individuals at risk for atherosclerosis early in life to enable early intervention using preventive measures may slow the atherosclerotic process and delay cardiovascular disease. Atherosclerosis can be assessed using non-invasive techniques, such as carotid intima-media thickness measurement (IMT CCA) (Ali et al. 2006). Atherosclerotic disease in one vascular bed indicates possible disease in others, so finding of atherosclerotic plaques in carotid or femoral area could predict the risk of coronary disease (Beckman et al. 2002, Lorenz et al. 2006). IMT CCA is superior to other methods since it is non-invasive, devoid of side effects, and reproducible. It also enables evaluation of the arterial wall rather than the lumen and provides a useful tool for early detection of atherosclerotic plaques in every age in the patient (Cobble and Bale 2010). It is also recommended by the American Heart Association as a non-invasive imaging parameter for detecting atherosclerosis (Greenland et al. 2000).

Therefore, in the present study we analyzed differences of determinants of preclinical atherosclerosis between T1DM and T2DM women. We studied differences in traditional risk factors of atherosclerosis (hypertension, smoking, lipids, metabolic control, and adiposity) and also in some emerging risk factors of atherosclerosis (vitamin D level).

\section{Patients and Methods}

Women with type $1(\mathrm{n}=203)$ and type 2 diabetes $(n=123)$ were examined in single center with regard to the presence of cardiovascular risk factors and the presence of preclinical atherosclerosis expressed as intima-media thickness in carotid (IMT CCA) and femoral arteries (IMT CFA) measured by ultrasound. Women were included according to age (older than 18 and younger than 58 years), and according to their willingness and ability to enter the study. We chose women only due to homogeneity of the group and because the women sex is generally less prone to cardiovascular disease, although diabetic premenopausal women are not physiologically protected against the vascular disease.

All women were examined regarding the presence of manifest cardiovascular disease, cardiovascular risk factors, microvascular complications (history of retinopathy, nephropathy) and treatment. In addition, anthropometric measurements (weight, height, waist and hip circumferences, body fat content), and blood pressure measurements were obtained in the standard manner. The blood pressure and heart rate were analyzed as mean values calculated from three measurements obtained by sphygmomanometer in an interval of one minute in supine position under resting condition. Women with history of current and past regular smoking were defined as smokers. Hypertension and dyslipidemia were defined exclusively by history (current or previous treatment) irrespectively on actual values of blood pressure and actual lipid levels. Body mass index (BMI) was calculated as weight in $\mathrm{kg}$ divided by squared height in meters. The borderline value for overweight was chosen as $25 \mathrm{~kg} / \mathrm{m}^{2}$ (NHLBI Obesity Education Initiative Expert Panel 1998). The waist circumference (WC) was measured by a flexible tape. The borderline value indicating pathological findings was defined as $80 \mathrm{~cm}$ according to the IDF consensus worldwide definition of the metabolic syndrome (Alberti et al. 2006). Waist-to-hip ratio (WHR) was calculated as the quotient of circumference of the waist and hip in $\mathrm{cm}$.

The IMT CCA and IMT CFA values were measured by ultrasound device (Toshiba Nemio MX, Japan) with Toshiba PLN-805AT linear array ultrasound transducer probe (frequency range of 6.0 to $12.0 \mathrm{MHz}$ ) in identical manner. The values of IMT were obtained from CCA, and common femoral artery (CFA) (mean value calculated from two values on both sides $=$ four values totally; in CCA measured in $1 \mathrm{~cm}$ distance from bulb on the far wall). All measures were provided by single experienced investigator (PP). The same ultrasound probe was used for measurement of subcutaneous fat layer (in mm) $1 \mathrm{~cm}$ distally from the umbilicus as well. The total body fat in \% was measured by Omron BF306 hand held 
body fat monitor.

Fasting venous blood samples were taken in the morning. All lab results were obtained from a certified lab. The HOMA-IR index was used to evaluate insulin resistance and was calculated as fasting serum insulin $(\mu \mathrm{U} / \mathrm{ml}) \times$ fasting plasma glucose $(\mathrm{mmol} / \mathrm{l}) / 22.5$ (GayosoDiz et al. 2013). The atherogenic index of plasma (AIP) was calculated as logarithm of TG/HDL ratio (Dobiasova and Frohlich 2001).

As dependent variables, IMT CCA and IMT CFA were analyzed, as independent variables, all other factors under study were analyzed. Statistical analysis was performed using SPSS Software for Windows (version 16, Chicago, IL, USA). Data are expressed as medians, standard deviations and percentages. Comparisons between groups or within the same group were made using the Wilcoxon $\mathrm{W}$ and Mann-Whitney $\mathrm{U}$ non parametric tests, respectively. Spearman rho correlation analysis was used to include cardiovascular risk factors. A $p$ value $<0.01$ was considered statistically significant in all types of examination. The test of equality of correlation coefficients was used to compare differences between women with T1DM and T2DM. The inter-assay variability of investigator (PP) was expressed as intra-class correlation and this value for IMT CCA was 0.918 and for IMT CFA 0.989 .

Table 1. Demographics and history data (all data are medians \pm SD).

\begin{tabular}{lccc}
\hline & $\begin{array}{c}\text { Type 1 diabetes } \\
\text { mellitus }\end{array}$ & $\begin{array}{c}\text { Type 2 diabetes } \\
\text { mellitus }\end{array}$ & $\boldsymbol{p}$ \\
\hline Nr of patients & 203 & 123 & \\
Age (years) & $35.4 \pm 10.8$ & $52.0 \pm 7.7$ & $<0.001$ \\
Age at diabetes onset (years) & $17.2 \pm 12.3$ & $41.0 \pm 9.2$ & $<0.001$ \\
Duration of diabetes (years) & $16.0 \pm 9.6$ & $8.0 \pm 7.1$ & $<0.001$ \\
Prevalence of smoking (\%) & 33.5 & 53.6 & $<0.001$ \\
Prevalence of hypertension (\%) & 23.2 & 75.6 & $<0.001$ \\
Prevalence of dyslipidemia (\%) & 14.3 & 59.4 & $<0.001$ \\
Prevalence of treatment by ACEI/ARB (\%) & 33.0 & 62.7 & $<0.001$ \\
Prevalence of hypolipidemic treatment (statins, & 11.3 & 53.7 & $<0.001$ \\
fibrates) (\%) & & & \\
Prevalence of known CV disease ischemic heart & 6.4 & 20.3 & $<0.005$ \\
disease, peripheral artery disease, and history of stroke & & & \\
(\%) & & & $n$ \\
Prevalence of retinopathy/retinopathy treatment & $35.0 / 46.5$ & $25.2 / 87.1$ & \\
(panretinal laser photocoagulation, vitrectomy etc.) & & & n.s. \\
(\%) & 22.7 & 32.5 & n.s. \\
Prevalence of known nephropathy (all kinds) (\%) & 6.9 & 16.3 & $<0.001$ \\
Prevalence of diabetic foot (\%) & $82.8 / 17.2$ & $40.6 / 59.4$ & \\
Periode present/postmenopausal (\%) & & &
\end{tabular}

ACEI $=$ inhibitors of angiotensinogen converting enzyme, $\mathrm{ARB}=$ angiotensin receptor blockers, $\mathrm{CV}=$ cardiovascular

\section{Results}

The median of age of T2DM and T1DM women was $52.0 \pm 7.7$, and $35.4 \pm 10.8$ years. The prevalence of smoking in T2DM and T1DM women was 53.6, and $33.5 \%$. The median age at diabetes onset in T2DM and T1DM women was $41.0 \pm 9.2$, and $17.2 \pm 12.3$ years. The median duration of diabetes in T2DM and T1DM women was $8.0 \pm 7.1$ and $16.0 \pm 9.6$ years. Prevalence of known cardiovascular disease (ischemic heart disease, peripheral artery disease, and history of stroke) in T2DM and T1DM women was 20.3 and $6.4 \%$. In T2DM women $59.4 \%$ and in T1DM women $17.2 \%$ women were postmenopausal. All these differences were statistically significant (Table 1). Significant differences in both groups under study were found in all anthropometric parameters (BMI, WHR, waist 
circumference), casual systolic and diastolic blood pressure values, pulse pressure, subcutaneous fat layer and body fat content and markers of preclinical atherosclerosis as well (Table 2). In lab results significantly different were triglyceride, HDL and HDL cholesterol values, hsCRP, fibrinogen, vitamin D, HOMA-IR values and atherogenic index of plasma between both groups of women under study (Table 3 ).

Table 2. Anthropometric data and subclinical atherosclerosis markers measurement (all data are medians \pm SD).

\begin{tabular}{lccc}
\hline & Type 1 diabetes mellitus & $\begin{array}{c}\text { Type 2 diabetes } \\
\text { mellitus }\end{array}$ & $\boldsymbol{p}$ \\
& & 123 & $<0.001$ \\
Nr of patients & 203 & $32.0 \pm 7.0$ & $<0.001$ \\
BMI (body mass index) $\left(\mathrm{kg} / \mathrm{m}^{2}\right)$ & $23.6 \pm 4.1$ & $0.9 \pm 0.1$ & $<0.001$ \\
WHR (waist-to-hip ratio) & $0.8 \pm 0.1$ & $105.0 \pm 15.1$ & $<0.001$ \\
Waist circumference $(\mathrm{cm})$ & $77.0 \pm 9.9$ & $134.0 \pm 18.8$ & $<0.001$ \\
Systolic blood pressure $(\mathrm{mm} \mathrm{Hg})$ & $120.0 \pm 16.0$ & $80.0 \pm 9.6$ & $<0.001$ \\
Diastolic blood pressure $(\mathrm{mm} \mathrm{Hg})$ & $76.0 \pm 9.1$ & $54.0 \pm 14.3$ & $\mathrm{n} . \mathrm{s}$. \\
Pulse pressure (mm Hg) & $46.0 \pm 11.7$ & $71.0 \pm 9.2$ & $<0.001$ \\
Heart rate (min ${ }^{-1}$ ) & $72.0 \pm 10.3$ & $33.7 \pm 17.7$ & $<0.001$ \\
Subcutaneous fat layer $(\mathrm{mm})$ & $19.9 \pm 11.3$ & $38.2 \pm 6.9$ & $<0.001$ \\
Total body fat $(\%)$ & $25.2 \pm 6.6$ & $0.75 \pm 0.43$ & $<0.001$ \\
IMT CCA (mm) & $0.50 \pm 0.14$ & $0.80 \pm 0.65$ & \\
IMT CFA (mm) & $0.60 \pm 0.42$ & & \\
\hline
\end{tabular}

IMT = intima-media thickness, $\mathrm{CCA}=$ common carotid artery, $\mathrm{CFA}=$ common femoral artery

Table 3. Laboratory results (all data are medians \pm SD).

\begin{tabular}{|c|c|c|c|}
\hline & $\begin{array}{c}\text { Type } 1 \text { diabetes } \\
\text { mellitus }\end{array}$ & $\begin{array}{c}\text { Type } 2 \text { diabetes } \\
\text { mellitus }\end{array}$ & $\mathbf{p}$ \\
\hline Nr of patients & 203 & 123 & \\
\hline Fasting glucose $(\mathrm{mmol} / \mathrm{l})$ & $8.7 \pm 4.7$ & $9.4 \pm 4.0$ & n.s. \\
\hline HOMA-IR index of insulin resistence & $0.9 \pm 12.0$ & $5.7 \pm 7.5$ & $<0.001$ \\
\hline $\mathrm{Hb}_{1} \mathrm{c}(\mathrm{mmol} / \mathrm{mol})$ IFCC calibration & $68 \pm 19$ & $68 \pm 25$ & n.s. \\
\hline Triglycerides (mmol/l) & $0.8 \pm 0.7$ & $1.9 \pm 1.6$ & $<0.001$ \\
\hline Total cholesterol (mmol/l) & $4.8 \pm 1.1$ & $4.9 \pm 1.1$ & n.s. \\
\hline HDL cholesterol ( $\mathrm{mmol} / \mathrm{l})$ & $1.7 \pm 0.4$ & $1.2 \pm 0.4$ & $<0.001$ \\
\hline LDL cholesterol (mmol/l) & $2.5 \pm 0.8$ & $2.9 \pm 0.9$ & $<0.005$ \\
\hline $\begin{array}{l}\text { Atherogenic index of plasma } \\
(A I P=\log T G / H D L)\end{array}$ & $-0.3 \pm 0.3$ & $0.2 \pm 0.3$ & $<0.001$ \\
\hline $\operatorname{Lp}(a)(m g / l)$ & $89.6 \pm 326.4$ & $75.9 \pm 491.9$ & n.s. \\
\hline$h s C R P(m g / l)$ & $1.0 \pm 3.4$ & $3.2 \pm 4.4$ & $<0.001$ \\
\hline Fibrinogen $(g / l)$ & $2.7 \pm 0.7$ & $3.1 \pm 0.8$ & $<0.005$ \\
\hline Creatinin $(\mu \mathrm{mol} / \mathrm{l})$ & $72.0 \pm 20.8$ & $70.0 \pm 37.4$ & n.s. \\
\hline U-albumin $(\mathrm{mg} / \mathrm{l})$ & $5.0 \pm 134.8$ & $8.4 \pm 346.8$ & n.s. \\
\hline$U$-alb/U-creatinin ratio $(\mathrm{mg} / \mu \mathrm{mol} / \mathrm{l})$ & $0.9 \pm 24.8$ & $1.3 \pm 91.7$ & n.s. \\
\hline Cystatin C clearence $\left(\mathrm{ml} / \mathrm{s} / 1.73 \mathrm{~m}^{2}\right)$ & $2.2 \pm 11.9$ & $1.9 \pm 6.1$ & n.s. \\
\hline 25-OH-vitamin $D($ nmol/l) & $44.7 \pm 28.6$ & $34.7 \pm 17.6$ & $<0.001$ \\
\hline
\end{tabular}


Table 4. Correlations and significance of carotid intima-media thickness (IMT CCA) and femoral intima-media thickness (IMT CFA).

\begin{tabular}{|c|c|c|c|c|c|c|c|c|}
\hline \multirow{3}{*}{$\begin{array}{l}\text { Spearman's rho } \\
\text { correlation }\end{array}$} & \multicolumn{4}{|c|}{ Carotid intima-media thickness (IMT CCA) } & \multicolumn{4}{|c|}{ Femoral intima-media thickness (IMT CFA) } \\
\hline & \multicolumn{2}{|c|}{$\begin{array}{c}\text { Type } 1 \text { diabetes } \\
\text { mellitus }\end{array}$} & \multicolumn{2}{|c|}{$\begin{array}{c}\text { Type } 2 \text { diabetes } \\
\text { mellitus }\end{array}$} & \multicolumn{2}{|c|}{$\begin{array}{c}\text { Type } 1 \text { diabetes } \\
\text { mellitus } \\
\end{array}$} & \multicolumn{2}{|c|}{$\begin{array}{c}\text { Type } 2 \text { diabetes } \\
\text { mellitus } \\
\end{array}$} \\
\hline & Correlation & $\mathbf{p}$ & Correlation & p & Correlation & $\mathbf{p}$ & Correlation & p \\
\hline Age & 0.524 & $<0.0001$ & 0.482 & $<0.0001$ & 0.572 & $<0.0001$ & 0.384 & $<0.0001$ \\
\hline $\begin{array}{l}\text { Diabetes mellitus } \\
\text { duration }\end{array}$ & 0.183 & $<0.01$ & 0.140 & n.s. & 0.272 & $<0.0001$ & 0.272 & n.s. \\
\hline Body mass index* & 0.297 & $<0.0001$ & 0.070 & n.s. & 0.295 & $<0.0001$ & 0.078 & n.s. \\
\hline $\begin{array}{l}\text { Waist } \\
\text { circumference* }\end{array}$ & 0.316 & $<0.0001$ & 0.236 & n.s. & 0.361 & $<0.0001$ & 0.204 & n.s. \\
\hline $\begin{array}{l}\text { Systolic blood } \\
\text { pressure }\end{array}$ & 0.334 & $<0.0001$ & 0.303 & $<0.001$ & 0.381 & $<0.0001$ & 0.216 & n.s. \\
\hline $\begin{array}{l}\text { Diastolic blood } \\
\text { pressure }\end{array}$ & 0.125 & n.s. & 0.103 & n.s. & 0.172 & $<0.05$ & 0.097 & n.s. \\
\hline Pulse pressure & 0.330 & $<0.0001$ & 0.303 & $<0.001$ & 0.360 & $<0.0001$ & 0.228 & n.s. \\
\hline $\begin{array}{l}\text { Subcutaneous fat } \\
\text { layer }\end{array}$ & 0.153 & $<0.01$ & 0.080 & n.s. & 0.225 & $<0.01$ & 0.184 & n.s. \\
\hline Body fat \%** & 0.410 & $<0.0001$ & 0.169 & n.s. & 0.431 & $<0.0001$ & 0.173 & n.s. \\
\hline $\begin{array}{l}\text { Severity of } \\
\text { neuropathy }\end{array}$ & 0.307 & $<0.001$ & 0.347 & $<0.001$ & 0.267 & $<0.001$ & 0.282 & $<0.001$ \\
\hline Fasting glucose* & 0.022 & n.s. & 0.299 & $<0.001$ & 0.281 & $<0.0001$ & 0.281 & $<0.0001$ \\
\hline$H b A 1 c^{*}$ & 0.026 & n.s. & 0.372 & $<0.0001$ & 0.084 & n.s. & 0.304 & $<0.0001$ \\
\hline Triglycerides* & 0.021 & n.s. & 0.304 & $<0.001$ & 0.153 & n.s. & 0.195 & n.s. \\
\hline LDL cholesterol & 0.018 & n.s. & 0.078 & n.s. & 0.086 & n.s. & 0.073 & n.s. \\
\hline HDL cholesterol* & 0.104 & n.s. & 0.420 & $<0.0001$ & 0.138 & n.s. & 0.223 & n.s. \\
\hline $\begin{array}{l}\text { Atherogenic index } \\
\text { of plasma* }\end{array}$ & 0.073 & n.s. & 0.390 & $<0.0001$ & 0.199 & n.s. & 0.209 & n.s. \\
\hline $\begin{array}{l}\text { Ualb/Ukrea } \\
\text { ratio }^{* *}\end{array}$ & 0.126 & n.s. & 0.305 & $<0.0001$ & 0.213 & n.s. & 0.370 & $<0.0001$ \\
\hline 25-OH-vitamin D & 0.084 & n.s. & 0.056 & n.s. & 0.182 & n.s. & 0.089 & n.s. \\
\hline Hormonal status & 0.229 & $<0.001$ & 0.368 & $<0.0001$ & 0.457 & $<0.0001$ & 0.330 & $<0.0001$ \\
\hline
\end{tabular}

* Significant differences between correlation coefficients in women with type 1 and 2 diabetes in IMT CCA, ** Significant differences between correlation coefficients in women with type 1 and 2 diabetes both in IMT CCA and IMT CFA

All T1DM women were treated by intensified insulin therapy $(45.8 \%$ of them by insulin pump therapy; the mean insulin dose was $0.62 \pm 0.18 \mathrm{IU} / \mathrm{kg}$ of body weight). T2DM women were treated by oral antidiabetics only ( $44.7 \%$ of all T2DM women); $53.6 \%$ of all T2DM had insulin therapy $(63.6 \%$ of them in the form of intensified therapy), most of them in combination with oral agents, $3 \%$ of T2DM women were on diet only.

Differences in risk factors for atherosclerosis between T1DM and T2DM women were observed as follows (Table 4): in T1DM women strong association between IMT CCA and body mass index, waist circumference, and total body fat was found in contrast to T2DM women. In T2DM women strong association between IMT CCA and fasting glucose, $\mathrm{HbA}_{1 \mathrm{c}}$, atherogenic index of plasma (log TG/HDL cholesterol) and albumin/creatinine ratio in urine was observed in contrast to T1DM women. In T1DM women, IMT CFA was associated with body fat content in contrast to T2DM women. In T2DM women, IMT CFA was associated with albumin/creatinine ratio in urine in contrast to T1DM women.

Based on these differences we focused on T1DM women with regard to association between IMT CCA and 
BMI and body fat. We divided T1DM women according to the BMI (less than $25 \mathrm{~kg} / \mathrm{m}^{2}$ and more than $25 \mathrm{~kg} / \mathrm{m}^{2}$ ), according to the $\mathrm{HbA}_{1 \mathrm{c}}$ level (less than $60 \mathrm{mmol} / \mathrm{mol}$ and more than $60 \mathrm{mmol} / \mathrm{mol}$ - calibration according to the IFCC), according to the body fat content (less than $30 \%$ and more than $30 \%$ of the body weight) and according to the waist circumference (less than $80 \mathrm{~cm}$ and more than $80 \mathrm{~cm}$ ), i.e. values significant for the risk assessment in this particular group. We have found increased IMT CCA in group with higher body fat content, higher waist circumference and higher BMI (Fig. 1 for BMI; data for body fat content and waist circumference not shown; all values $\mathrm{p}<0.01)$. The subclinical atherosclerosis markers weren't associated with $\mathrm{HbA}_{1 \mathrm{c}}$ level $(\mathrm{p}=\mathrm{n}$.s.) (not shown).

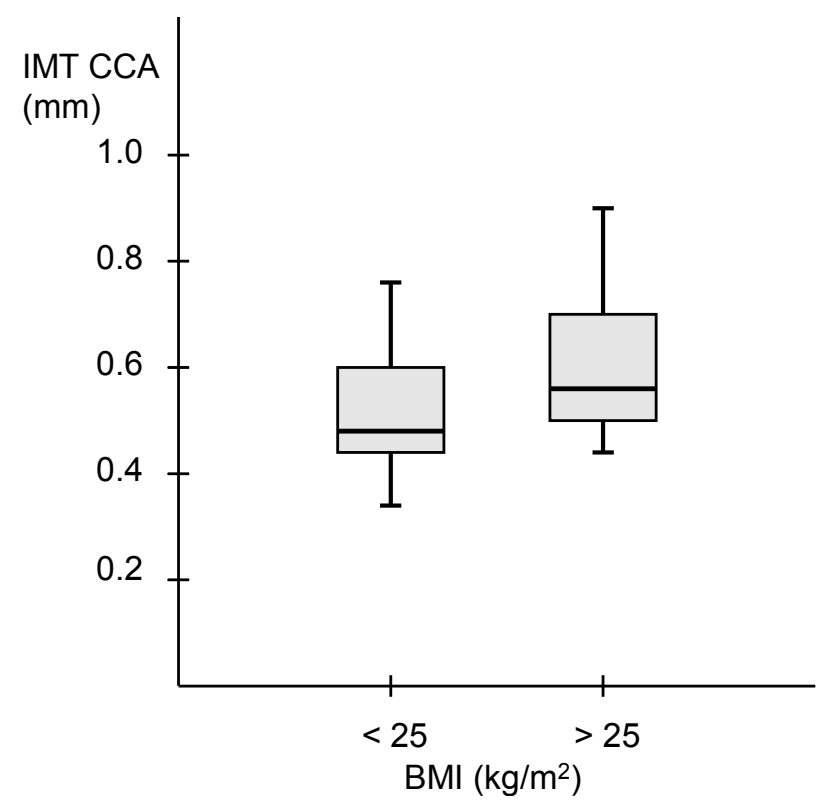

Fig. 1. Body mass index (BMI) category (less than $25 \mathrm{~kg} / \mathrm{m}^{2}$ and more than $25 \mathrm{~kg} / \mathrm{m}^{2}$ ) and intima-media thickness IMT CCA in T1DM women. IMT CCA = intima-media thickness common carotid artery, BMI = body mass index, T1DM = type 1 diabetes mellitus

The IMT CCA was significantly associated with age, age at onset of diabetes, presence and treatment of hypertension and dyslipidemia (as well as to the systolic blood pressure and pulse pressure) and history of cardiovascular diseases and postmenopausal status (data not shown) both in T1DM and T2DM women.

The IMT CFA was significantly associated in both T1DM and T2DM women with age, diabetes duration, presence of the diabetic foot syndrome, nephropathy (as well as to albumin/creatinine ratio in urine), hypertension and its treatment (as well as to the systolic blood pressure and pulse pressure), dyslipidemia and its treatment, history of the cardiovascular diseases, postmenopausal status and IMT CCA. In T1DM, the IMT CFA was significantly associated with body fat content, severity of the neuropathy, presence of the retinopathy and its treatment ( $=$ it means more serious forms of retinopathy), smoking and lipid parameters (atherogenic index of the plasma), while in T2DM women the statistically significant correlation to the $\mathrm{HbA}_{1 \mathrm{c}}$ and HDL-cholesterol value was found (Table 4). However, there were no differences observed between correlation coefficients regarding these factors.

Vitamin D levels were low in T1DM and T2DM women and we observed no correlation to the markers of subclinical atherosclerosis in both groups (Tables 3 and 4). The comparison of smokers to the non-smokers didn't reveal significant differences between both types of diabetes in any factor under study. Although we have found significant differences in hormonal status between both groups of women and significant associations of postmenopausal status with IMT CCA and IMT CFA were found in both groups, no significant difference between two groups of women under study was present.

\section{Discussion}

We found different determinants for subclinical atherosclerosis in carotid and femoral arteries between T1DM and T2DM women. Preclinical atherosclerosis in T1DM women was strongly associated with factors reflecting body fat and its distribution, while in T2DM women preclinical atherosclerosis was associated with markers reflecting glucose and lipid metabolic disorders. The association with BMI and body fat in T2DM wasn't found probably due to low number of lean T2DM women (only $10 \%$ of them have $\mathrm{BMI}<25 \mathrm{~kg} / \mathrm{m}^{2}$ ).

Our group of T1DM women was younger but with longer duration of the disease in comparison to the group of T2DM women. Very important fact is that the metabolic control was similar and not very good in both groups; nevertheless, we have observed the strong impact of $\mathrm{HbA}_{1 \mathrm{c}}$ level on subclinical atherosclerosis only in T2DM and not in T1DM women. The impact of the diabetes is, therefore, in T1DM patients reflected probably more by its duration than actual control.

In this study the markers of subclinical atherosclerosis were strongly associated with traditional risk factors (age, duration of diabetes, hypertension and dyslipidemia), with already described differences 
between T1DM and T2DM women. In T1DM patients, similar observation was described in recent papers as well. Pinto et al. (2014) compared 81 otherwise healthy young T1DM patients to 35 sex and age matched healthy adults (mean age $19.5 \pm 4.0$ years) with $9.8 \pm 4.8$ years of duration of diabetes. The male sex, weight and T1DM were positively associated with a thicker IMT CCA and weight was the most common variable that was positively related to IMT CCA in both healthy and T1DM patients. The HDL cholesterol was the main lipid fraction negatively related to IMT CCA in T1DM group. This study included small number of participants and patients with statin therapy, smoking and bad metabolic control $\left(\mathrm{HbA}_{1 \mathrm{c}}>9.0 \%\right.$ according to the DCCT) were excluded. In our study the statins were used in $11.3 \%$ of T1DM patients (and patients treated by statins are prone to display a reduction in IMT CCA), so there could be supposed that after exclusion of patients treated by statin therapy the results could be even more significant. Faienza et al. (2013) enrolled in their study 71 young subjects (mean age 12.86 \pm 2.38 ), 24 of them were obese, 26 of them had T1DM and 21 were healthy controls. Anthropometric examination, both systolic and diastolic blood pressure and lab results were obtained in all subjects and very similar statistical analysis was performed. This study suggests the IMT CCA was thicker in obese and T1DM patients in comparison to the healthy children, even in obese children the IMT CCA was thicker than in T1DM patients. In this study also no association between IMT CCA and $\mathrm{HbA}_{1 \mathrm{c}}$ at the time of visit was observed in T1DM patients. Kim et al. (2014) have published similar observation - the glycated albumin to glycated hemoglobin ratio wasn't associated to carotid atherosclerosis in T1DM patients, while in T2DM patients this ratio is known to be associated to IMT CCA. In the SEARCH study (Urbina et al. 2013) adolescents and young adults (mean age $18.8 \pm 3.3$ years) were examined to determine the IMT CCA. T1DM patients (402 patients) were compared to matched healthy controls (206 participants). Youth with T1DM had thicker IMT CCA, which remained significantly different after adjustment for demographic and cardiovascular risk factors. Age, sex, adiposity and systolic blood pressure were consistent significant determinants of IMT CCA. Rathsman et al. (2012) focused on IMT CCA in adolescents and young adults with T1DM (20 patients, age 14-20) without clinical characteristics of metabolic syndrome and compared them with healthy controls. The IMT CCA was increased in diabetic participants and associated negatively with insulin sensitivity (measured by hyperinsulinemic euglycemic clamp) and positively with waist circumference. The association with BMI, triglycerides, HDL-cholesterol and $\mathrm{HbA}_{1 \mathrm{c}}$ wasn't find.

Obesity is well established risk factor for atherosclerosis, but the underlying mechanism for this association is poorly understood. In recent years, evidence has demonstrated that abdominal accumulation of fat tissue produces the most profound metabolic abnormalities and is associated with an increased risk of atherosclerotic CVD (Nissen et al. 2008). Adipose tissue is now recognized as an independent and active endocrine organ. Various adipokines, such as leptin, tumor necrosis factor- $\alpha(\mathrm{TNF}-\alpha)$, resistin, and adiponectin significantly affect obesity-related metabolic diseases by controlling fat metabolism, energy homeostasis, and insulin sensitivity. Independent of their effects on glucose and fat metabolism, some adipokines have been regarded recently as direct links between obesity and atherosclerosis because of their influence on the function of endothelial cells, arterial smooth muscle cells, and macrophages in vessel walls (Yoo and Choi 2014). The mechanisms associated with accelerated atherosclerosis observed in the insulin resistance-associated conditions are still under investigation, but it is believed that a decline in the bioavailability of nitric oxide (NO) as an expression of endothelial dysfunction and an increase in reactive oxygen species (ROS) are the most crucial factors (Du et al. 2013).

We didn't find any association between parameters of subclinical atherosclerosis and vitamin D levels in any group under study - women with T1DM and T2DM. Similar observation in T1DM patients was published by Sachs et al. (2013).

Our results suggest that the common factor involved both in endothelial dysfunction and thickness of the internal layer of the arterial wall could be excessive body fat with extensive production of adipokines. In T1DM patients the increase in the body fat accumulation could be caused by insulin application. The inappropriate dose of insulin applied into the peripheral subcutaneous tissue (i.e. no physiological way as in healthy subjects) could be connected to the grow effects of insulin and disturbances of the endothelial function.

The waist circumference reflects the abdominal adiposity and insulin resistance that could play a role in atherosclerosis development even in relatively young and relatively lean T1DM women yet before traditional cardiovascular risk factors like blood lipids and blood 
pressure are detected as determinants of atherosclerosis. Although the values of IMT CCA and IMT CFA were pretty in normal range in T1DM women, the values near the upper normal limit in women with higher BMI could be a "shadow zone" for intervention, especially for the intervention on insulin resistance, BMI and body fat content.

The limitations of our study are its crosssectional character and focus only on women in predefined age range. In addition, the distribution of risk factors was different in both groups under study. On the other hand, this is single center study done by one examiner (PP) with low and definitely acceptable variability in obtained measurements. In addition, multiple risk factors were examined in relatively high number of participants in a standardized manner. Many recently published studies compared only relatively small amount of diabetic patients to healthy controls, examined only young adults and adolescents. To our knowledge, no study focused on differences in patients of both types of diabetes and including larger number of T1DM patients of older age is available.

Based on our results, prevention of atherosclerosis and macrovascular disease could have different priorities in younger T1DM women compared to their counterparts with T2DM. Therefore, in T1DM women the focus should be targeted not only on blood lipids and on blood pressure but also on ideal body weight and body fat content. Our findings should be proved in prospective studies.

\section{Conflict of Interest}

There is no conflict of interest.

\section{Acknowledgements}

Supported by the project (Ministry of Health, Czech Republic) for conceptual development of research organization 00064203 (University Hospital Motol, Prague, Czech Republic)

\section{References}

ALBERTI KGMM, ZIMMET P, SHAW J: Metabolic syndrome - a new world-wide definition. A Consensus Statement from the International Diabetes Federation. Diabet Med 23: 469-480, 2006.

ALI YS, REMBOLD KE, WEAVER B, WILLS MB, TATAR S, AVERS CR, REMBOLD CM: Prediction of major adverse cardiovascular events by age-normalized carotid intimal medial thickness. Atherosclerosis 187: 186$190,2006$.

BECKMAN JA, CREAGER MA, LIBBY P: Diabetes and atherosclerosis. Epidemiology, pathophysiology and management. JAMA 287: 2570-2581, 2002.

BERENSON GS, SRINIVASAN SR, BAO W, NEWMAN WP, TRACY RE, WATTIGNEY WA: Association between multiple cardiovascular risk factors and atherosclerosis in children and young adults. The Bogalusa Heart Study. N Engl J Med 338: 1650-1656, 1998.

BOOTH GL, KAPRAL MK, FUNG K, TU JV: Relation between age and cardiovascular disease in men and women with diabetes compared with non-diabetic people: a population-based retrospective cohort study. Lancet $\mathbf{3 6 8}$ : 29-36, 2006.

CLELAND SJ, FISHER BM, COLHOUN HM, SATTAR N, PETRIE JR: Insulin resistance in type 1 diabetes: what is 'double diabetes' and what are the risks? Diabetologia 56: 1462-1470, 2013.

COBBLE M, BALE B: Carotid intima-media thickness: knowledge and application to everyday practice. Postgrad Med 122: 10-18, 2010.

DAILEY G, WANG E: A review of cardiovascular outcomes in the treatment of people with type 2 diabetes. Diabetes Ther 5: 385-402, 2014.

DIABETES DRAFTING GROUP: Prevalence of small vessel and large vessel disease in diabetic patients from 14 centers. The World Health Organization Multinational Study of Vascular Disease in Diabetics. Diabetologia 28 (Suppl): 615-640, 1998.

DOBIASOVA M, FROHLICH J: The plasma parameter log (TG/HDL-C) as an atherogenic index: correlation with lipoprotein particle size and esterification rate in apoB-lipoprotein-depleted plasma $\left(\mathrm{FER}_{\mathrm{HDL}}\right)$. Clin Biochem 34: 583-588, 2001. 
DU F, VIRTUE A, WANG H, YANG XF: Metabolomic analyses for atherosclerosis, diabetes, and obesity. Biomark Res 1: 17, 2013.

FAIENZA MF, ACQUAFREDDA A, TESSE R, LUCE V, VENTURA A, MAGGIALETTI N, MONTEDURO M, GIORDANO P, CAVALLO L: Risk factors for subclinical atherosclerosis in diabetic and obese children. Int $J$ Med Sci 10: 338-343, 2013.

GAYOSO-DIZ P, OTERO-GONZÁLEZ A, RODRIGUEZ-ALVAREZ MX, GUDE F, GARCÍA F, DE FRANCISCO A, QUINTELA AG: Insulin resistance (HOMA-IR) cut-off values and the metabolic syndrome in a general adult population: effect of gender and age: EPIRCE cross-sectional study. BMC Endocr Disord 13: 47, 2013.

GREENLAND P, ABRAMS J, AURIGEMMA GP, BOND MG, CLARK LT, CRIQUI MH, CROUSE JR, FRIEDMAN L, FUSTER V, HEMINGTON DM, KULLER LH, RIDKER PM, ROBERTS WC, STANFORD W, STONE N, SWAN HJ, TAUBERT KA, WEXLER L: Prevention Conference V: Beyond secondary prevention: identifying the high-risk patient for primary prevention: noninvasive tests of atherosclerotic burden: Writing Group III. Circulation 101: E16-E22, 2000.

HAFFNER SM, LEHTO S, RÖNNEMAA T, PYÖRÄLÄ K, LAAKSO M: Mortality from coronary heart disease in subjects with type 2 diabetes and in nondiabetic subjects with and without prior myocardial infarction. $N$ Engl J Med 339: 229-234, 1998.

KIM HM, LEE BW, SONG YM, KIM WJ, CHANG HJ, CHOI DH, YU HT, KANG E, CHA BS, LEE HC: Potential association between coronary artery disease and the inflammatory biomarker YKL-40 in asymptomatic patients with type 2 diabetes mellitus. Cardiovasc Diabetol 11:84, 2012.

KIM W, KIM KJ, LEE BW, KANG ES, CHA BS, LEE HC: The glycated albumin to glycated hemoglobin ratio might not be associated with carotid atherosclerosis in patients with type 1 diabetes. Diabetes Metab J 38: 456-463, 2014.

LORENZ MW, VON KEGLER S, STEINMETZ H, MARKUS HS, SITZER M: Carotid intima-media thickening indicates a higher vascular risk across a wide age range: prospective data from the Carotid Atherosclerosis Progression Study (CAPS). Stroke 37: 87-92, 2006.

MOON JH, CHAE MK, KIM KJ, KIM HM, CHA BS, LEE HC, KIM YJ, LEE BW: Decreased endothelial progenitor cells and increased serum glycated albumin are independently correlated with plaque-forming carotid artery atherosclerosis in type 2 diabetes patients without documented ischemic disease. Circ J 76: 2273-2279, 2012.

MUNGER MA, HAWKINS DW: Atherothrombosis: epidemiology, pathophysiology, and prevention. $J$ Am Pharm Assoc 44 (2 Suppl 1): S5-S12, 2004.

NHLBI OBESITY EDUCATION INITIATIVE EXPERT PANEL ON THE IDENTIFICATION, EVALUATION, AND TREATMENT OF OBESITY IN ADULTS (US): Clinical Guidelines on the Identification, Evaluation, and Treatment of Overweight and Obesity in Adults. The Evidence Report. Obes Res 6 (Suppl 2): 51S-209S, 1998.

NISSEN SE, NICHOLLS SJ, WOLSKI K, RODÉS-CABAU J, CANNON CP, DEANFIELD JE, DESPRÉS JP, KASTELEIN JJ, STEINHUBL SR, KAPADIA S, YASIN M, RUZYLLO W, GAUDIN C, JOB B, HU B, BHATT DL, LINCOFF AM, TUZCU EM; STRADIVARIUS INVESTIGATORS: Effect of rimonabant on progression of atherosclerosis in patients with abdominal obesity and coronary artery disease: the STRADIVARIUS randomized controlled trial. JAMA 299: 1547-1560, 2008.

PINTO CS, LANA JM, GABBAY MA, DE SA Jr, DIB SA: HDL cholesterol levels and weight are the main determinants of subclinical atherosclerosis in the young with type 1 diabetes and suitable glycemic control. Diab Vasc Dis Res 11: 125-128, 2014.

RATHSMAN B, ROSFORS S, SJÖHOLM A, NYSTRÖM T: Early signs of atherosclerosis are associated with insulin resistance in non-obese adolescent and young adults with type 1 diabetes. Cardiovasc Diabetol 11:145, 2012.

SACHS MC, BRUNZELL JD, CLEARY PA, HOOFNAGLE AN, LACHIN JM, MOLITCH ME, STEFFES MW, ZINMAN B, DE BOER IH; DIABETES CONTROL AND COMPLICATIONS TRIAL/EPIDEMIOLOGY OF DIABETES INTERVENTIONS AND COMPLICATIONS STUDY RESEARCH GROUP: Circulating vitamin D metabolites and subclinical atherosclerosis in type 1 diabetes. Diabetes Care 36: 2423-2429, 2013. 
SCHAUER IE, SNELL-BERGEON JK, BERGMAN BC, MAAHS DM, KRETOWSKI A, ECKEL RH, REWERS M: Insulin resistance, defective insulin-mediated fatty acid suppression, and coronary artery calcification in subjects with and without type 1 diabetes. The CACTI Study. Diabetes 60: 306-314, 2011.

SONG SO, KIM KJ, LEE BW, KANG ES, CHA BS, LEE HC: Serum glycated albumin predicts the progression of carotid arterial atherosclerosis. Atherosclerosis 225: 450-455, 2012.

URBINA EM, DABELEA D, D'AGOSTINO RB Jr, SHAH AS, DOLAN LM, HAMMAN RF, DANIELS SR, MARCOVINA S, WADWA RP: Effect of type 1 diabetes on carotid structure and function in adolescents and young adults. The SEARCH CVD study. Diabetes Care 36: 2597-2599, 2013.

YOO HJ, CHOI KM: Adipokines as a novel link between obesity and atherosclerosis. World J Diabetes 5: 357-363, 2014. 